\title{
Caracterização Climatológica da Cidade de Manaus/AM
}

Duany Thainara Corrêa da Silva ${ }^{1}$, Natan Barbosa Almada ${ }^{1}$, Letícia Victória dos Santos Matias ${ }^{1}$, Ana Caroline da Silva Macambira ${ }^{1}$, Gabriel Brito Costa ${ }^{1}$, João Thiago Rodrigues de Sousa ${ }^{1}$ \& Marcelo de Almeida Heidemann ${ }^{1}$

1 Universidade Federal do Oeste do Pará/UFOPA, Brasil.<duanythaynara@gmail.com, natanalmada@gmail.com, Lleticia005@gmail.com, karoline_macambira@hotmail.com, gabrielbritocosta@gmail.com, thiagronomo@yahoo.com.br, marceloaheidemann@hotmail.com>.

RESUMO - Usando as informações obtidas para as diversas variáveis meteorológicas disponíveis da estação meteorológica convencional situada na cidade de Manaus/AM, no período de 1961 a 2017, caracterizaram-se os padrões sazonais climatológicos da cidade. Foram avaliadas as variabilidades sazonais e a possível influência de fenômenos de grande escala sobre elas, bem como a caracterização dos aspectos climatológicos locais. As variáveis meteorológicas avaliadas foram: temperatura e umidade relativa do ar, acumulados médios anuais de precipitação, médias de evaporação, horas de brilho solar e os padrões de direção e velocidade do vento. Fenômenos de grande escala, como o ENOS (El Niño Oscilação Sul), associaram-se com os extremos das variáveis meteorológicas, principalmente entre os anos de ocorrência de El Niño que se correlacionaram com os anos mais quentes e secos, e os de La Niña, que se associaram a anos mais frios e chuvosos. Evidenciou-se a tendência de aumento das médias de temperatura com consequente diminuição das médias de umidade relativa do ar, resultante, provavelmente, do efeito do crescimento urbanístico na cidade nos últimos anos, ocasionando recordes máximos de temperatura do ar e mínimo de umidade relativa na série avaliada.

Palavras-chave: ENOS; variabilidade climática; urbanização.

\section{Climatological Characterization of Manaus City/AM}

ABSTRACT - Using the information obtained for the various meteorological variables available from the conventional meteorological station located in the city of Manaus/AM, from 1961 to 2017, the city's climatological seasonal patterns were characterized. Seasonal variability and the possible influence of large-scale phenomena on them were evaluated, as well as the characterization of climatological aspects local. The meteorological variables evaluated were: temperature and relative humidity of the air, accumulated annual average precipitation, evaporation averages, hours of solar brightness and wind speed and direction patterns. Large-scale phenomena, such as ENOS (El Niño Oscilação Sul), were associated with the extremes of meteorological variables, mainly between the years of occurrence of El Niño that correlated with the hotter and drier years and those of La Niña that have been associated with colder and rainier years. The trend of increasing temperature averages was evident, with a consequent decrease in the average relative humidity of the air, probably resulting from the effect of urban growth in the city in recent years, causing maximum air temperature records and minimum relative humidity in the evaluated series.

Keywords: ENSO; climate variability; urbanization.

\section{Caracterización Climatológica de la Ciudad de Manaus/AM}

RESUMEN - A partir de la información obtenida para las distintas variables meteorológicas disponibles de la estación meteorológica convencional ubicada en la ciudad de Manaus/AM, de 1961 a 2017, se caracterizaron los patrones estacionales climatológicos de la ciudad. Se evaluó la variabilidad estacional y la posible influencia de fenómenos de gran escala sobre las mismas, así como la caracterización de aspectos climatológicos locales. Las variables meteorológicas evaluadas fueron: temperatura y humedad relativa del aire, precipitación promedio anual acumulada, promedios de evaporación, horas de brillo solar y patrones de velocidad y dirección del viento. Fenómenos de gran escala, como ENOS (El Niño Oscilação Sul), se asociaron con los extremos de las variables meteorológicas, principalmente entre los años de ocurrencia de El Niño que se correlacionaron con los años más calientes y secos y los de La Niña que se han asociado. con años más fríos y lluviosos. Se 
evidenció la tendencia al aumento de los promedios de temperatura, con la consecuente disminución de la humedad relativa promedio del aire, probablemente como resultado del efecto del crecimiento urbano en la ciudad en los últimos años, provocando registros de temperatura máxima del aire y humedad relativa mínima en la serie evaluada.

Palabras clave: ENOS; variabilidad climática; urbanización.

\section{Introdução}

Os estudos sobre ilhas de calor iniciaram com Luke Howard (publicado sobre o clima de Londres, em 1818) e Emile Renou (sobre o clima de Paris) (Gartland, 2010; Aguiar, 2017). Com base nesses estudos, foi possível começar a compreender o clima urbano até se desenvolver o conceito de "ilha de calor", em 1960, com os estudos de Gordon Manley (Alcoforado, 1993; Aguiar, 2017).

Silva \& Aguiar (2012) realizaram estudos na região de Manaus, com o registro de temperaturas coletadas por estações meteorológicas e de dados coletados em dez pontos móveis, levando em consideração a área construída e a intensidade do uso do espaço urbano. Seus resultados demonstraram uma incidência da ocorrência do fenômeno ilha de calor, na área do Aeroclube de Manaus, bem como a ocorrência em outros locais da cidade, sempre com as temperaturas mais elevadas. Ainda segundo os autores, essas áreas têm alta densidade populacional $e$ o intenso fluxo de veículos, o que justificaria tais padrões. Essas modificações do uso do solo e da paisagem local ao longo dos anos não influenciam apenas a temperatura do ar, mas também as diversas variáveis meteorológicas, como a precipitação, por exemplo.

A variabilidade espaço-temporal da precipitação pluviométrica na região Amazônica ocorre de forma irregular, apresentando marcante variação das médias anuais para os totais de precipitação, com uma variação de aproximadamente $6.000 \mathrm{~mm}$ nas encostas dos Andes a aproximadamente $1.600 \mathrm{~mm}$ na região ecotonal da Amazônia fronteira com o cerrado do Planalto Central Brasileiro (Salati, 1983) e (Ferreira et al., 2005). Fisch et al. (1998) mostraram que a estação de chuvas ou a forte atividade convectiva ocorre entre os meses de novembro a março, já os meses entre maio e setembro compreende o período de seca e os meses de abril e outubro como meses de transição entre um regime e outro.

Molion (1993) apresentou os principais sistemas de tempo de escala sinótica que afetam a região amazônica: 1 - Zona de Convergência Intertropical (ZCIT); 2 - Linhas de Instabilidade da Amazônia (LI); 3 - Zona de Convergência do Atlântico Sul (ZCAS); 4 - Jatos de Baixos Níveis (JBN); e 5 - Alta da Bolívia (AB). Sendo que, além desses fenômenos, outros podem ocorrer em escala menor afetando as condições meteorológicas em escala local, como as brisas marítimas e terrestres. Também os efeitos dos fenômenos de grande escala, como o El Niño - Oscilação do Sul (ENOS) no clima da América do Sul, têm sido bastante estudados, e em particular as alterações na célula de Walker (Souza et al., 2005); (Souza \& Ambrizzi, 2002) decorrente do aquecimento anômalo das águas oceânicas.

Dado o exposto, o conhecimento dos aspectos climatológicos e os possíveis impactos de eventos climáticos extremos em uma cidade de grande porte como Manaus gera material científico para auxiliar no desenvolvimento de políticas públicas de mitigação dos efeitos das mudanças climáticas e se compreender a variabilidade climática local para se ter um planejamento urbano eficiente, motivação principal deste trabalho.

\section{Material e Métodos}

\section{Área de Estudo}

A localização da estação de Manaus/AM (Figura 1) está nas coordenadas geográficas $03^{\circ} 11^{\prime}$ de latitude Sul e 59 $95^{\prime}$ de longitude Oeste. Situado na zona sul da cidade, em um raio de $100 \mathrm{~m}$ da estação cerca de $9,8 \%$ da área é vegetada, 48,5\% de área construída e 41,7\% de solo exposto (Aguiar, 2017), sendo que o período de dados considerado é de 1961 a 2017.

\section{Dados}

O banco de dados meteorológicos para o ensino e pesquisa (BDMEP) é usado para apoiar as atividades de ensino, pesquisa e outras aplicações em meteorologia, hidrologia, recursos hídricos, saúde pública, ciências ambientais $e$ nas demais áreas correlatas. Ele abriga os dados meteorológicos horários, diários e mensais em 


\section{LOCALIZAÇÃo DA ESTAÇÃo METEOROLOLÓGICA}

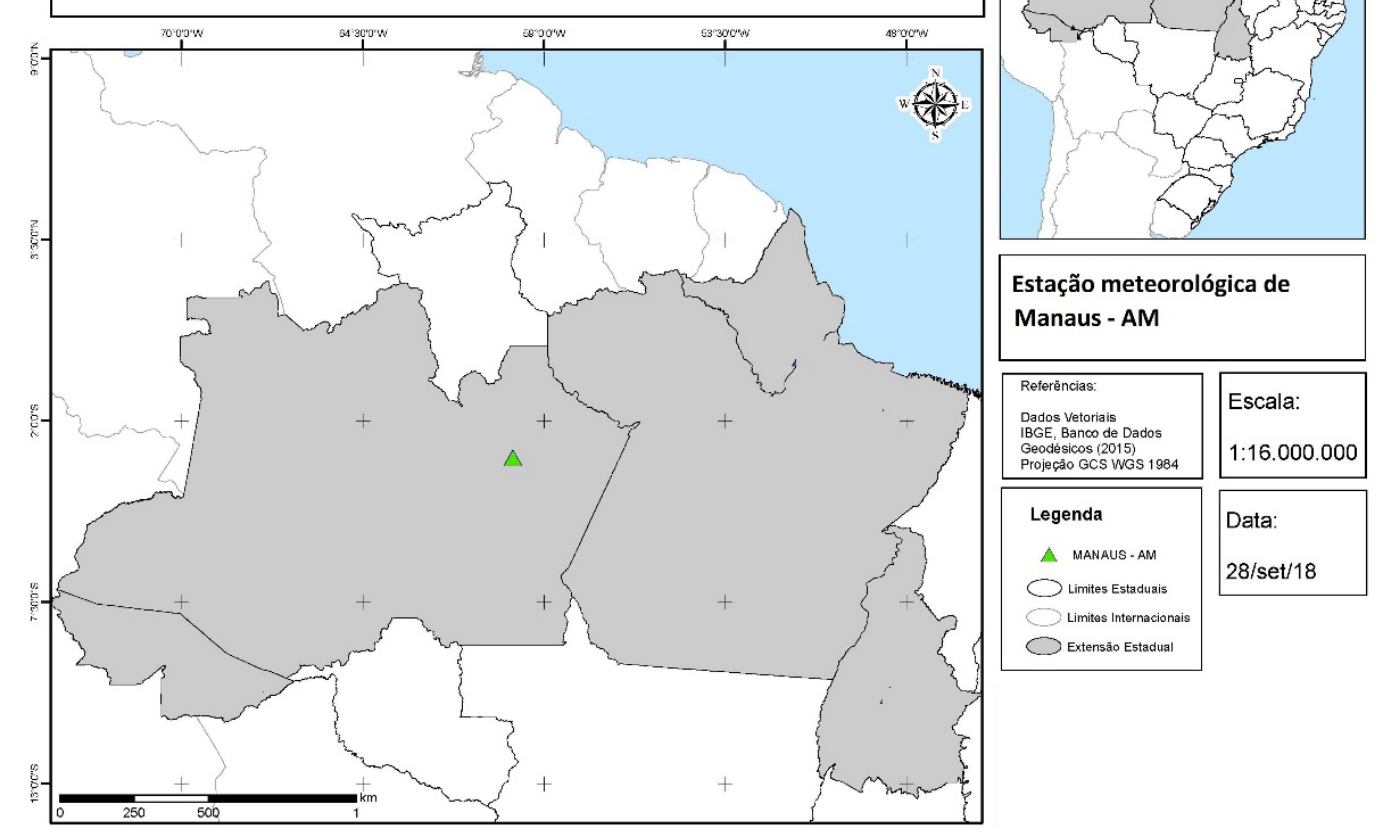

Figura 1 - Localização da estação meteorológica (município de Manaus) no estado do Amazonas.

formato digital, referentes a séries históricas da rede de estação pertencentes ao Instituto Nacional de Meteorologia (INMET), possuindo um total de cerca de 3 milhões de informações referentes às medições diárias e de acordo com as normas técnicas internacionais da Organização Meteorológica Mundial (Lemos, 2014).

Nele estão acessíveis os dados diários, a partir de 1961, das estações em funcionamento no Brasil. Para as séries de dados históricos referentes a períodos anteriores a 1961, estes ainda não foram digitalizados, e, portanto, estão indisponíveis no BDMEP. As variáveis meteorológicas disponibilizadas para consultas $e$ download no BDMEP são: a precipitação ocorrida nas últimas 24 horas, a temperatura do bulbo seco $e$ a temperatura do bulbo úmido, as temperaturas máxima, mínima e média, a umidade relativa do ar, a pressão atmosférica ao nível da estação, a insolação, a direção e a velocidade do vento, a evaporação, o número de horas de insolação, a visibilidade e a nebulosidade. Os valores de umidade relativa ar consideram observações realizadas nos horários sinóticos das 12, 18 e 24 horas UTC (Tempo Universal Coordenado, em português) que correspondem às 9,15 e 21 horas local.

\section{Cálculo da temperatura média compensada}

Por se tratar de uma série temporal, se faz necessário o controle da qualidade de dados. $\mathrm{O}$ objetivo do controle de qualidade é identificar as inconsistências no processo de registro, formatação, transmissão e arquivamento dos dados (WMO - $\left.N^{\circ} 1186,2003\right)$. Neste controle envolve, por exemplo, a detecção de erros nos dados plotados e de dados faltantes, a consistência interna, a coerência espacial e temporal, a verificação da homogeneidade dos dados, a correção dos dados, o preenchimento de falhas adequado $e$ entres outras técnicas. A temperatura compensada média é calculada através da fórmula utilizada pelo INMET:

$$
\text { TMédiaCompensada }\left({ }^{\circ} \mathrm{C}\right)=\frac{T 09 h+2 x T 21 h+T M i n+T M a x}{5}
$$

Onde T09h é a temperatura média das 09:00 horas local, T21h é temperatura média das 21:00 horas local (T21); temperatura máxima média (TMAX) e temperatura média mínima (TMIN). Plotaram-se gráficos com médias diárias das variáveis, boxplots do conjunto de dados e a densidade de dados por mês. Associações entre as variáveis meteorológicas e as ocorrências de anos 
de El Niño e La Niña fortes ou moderados tiveram por base o Oceanic Niño Index (ONI), disponível em:

(https://origin.cpc.ncep.noaa.gov/products/ analysis_monitoring/ensostuff/ONI_v5.php),

com limiares de anomalia considerados acima ou abaixo de $0.5^{\circ} \mathrm{C}$, que mostra dados sobre a região de Niño $3.4\left(5^{\circ} \mathrm{N}-5^{\circ} \mathrm{S}, 120^{\circ}-170^{\circ} \mathrm{W}\right)$. Os boxplots, gráficos e demais análises estatísticas foram feitas em linguagem $\mathrm{R}$, disponível em:

https://www.r-project.org/

\section{Resultados e Discussão}

Médias diárias de temperatura média compensada do ar (Figura 2) e médias diárias de umidade relativa do ar (Figura 3) na cidade de Manaus, entre os anos de 1961 e 2017, são mostradas a seguir. A linha preta indica a média móvel dos dados, onde os dados mais próximos do mínimo $\left(11,4^{\circ} \mathrm{C}\right)$ são amostrados em azul, e os mais próximos do máximo $\left(34^{\circ} \mathrm{C}\right)$ em vermelho. Já os demais dados, em verde, estão próximos a temperatura média $\left(26,9^{\circ} \mathrm{C}\right)$.

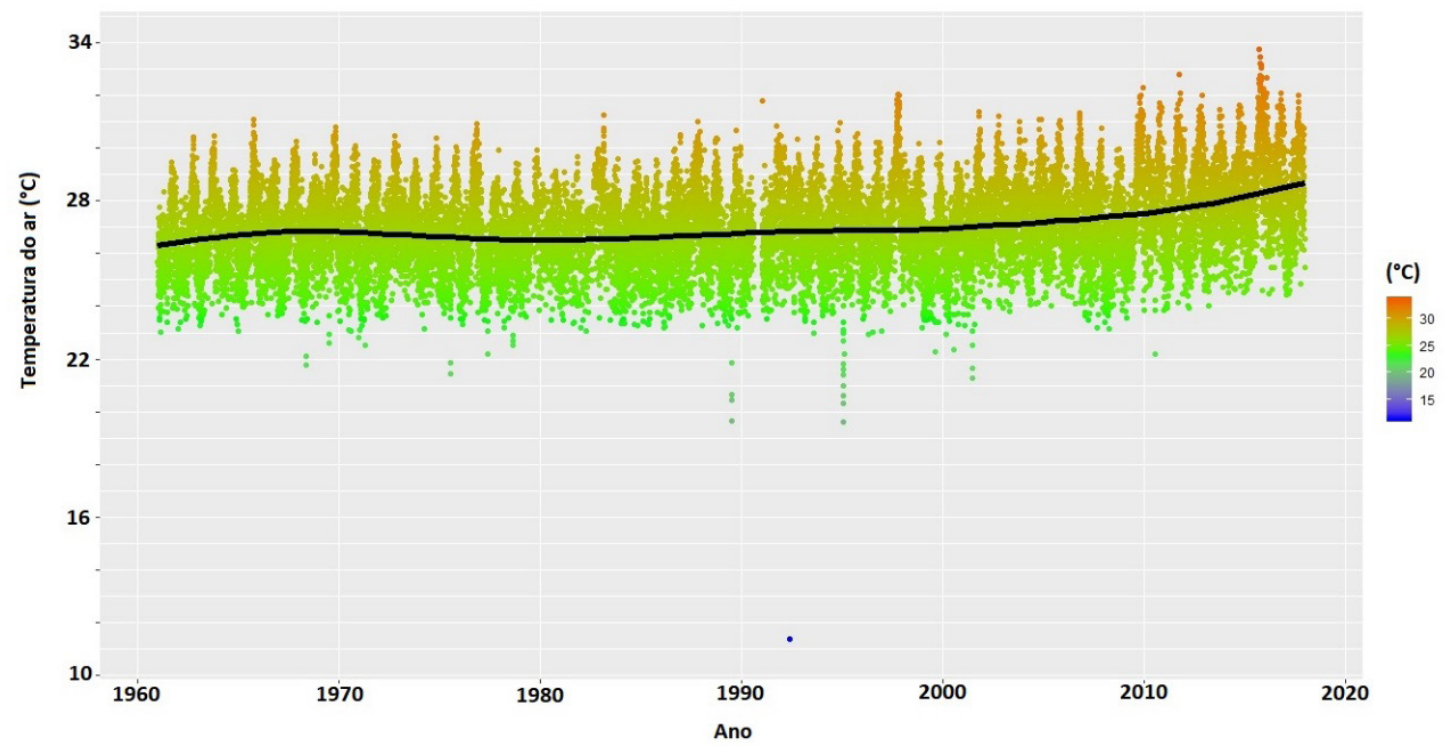

Figura 2 - Médias diárias de temperatura do ar da cidade de Manaus/AM para o período de 1961 a 2017.

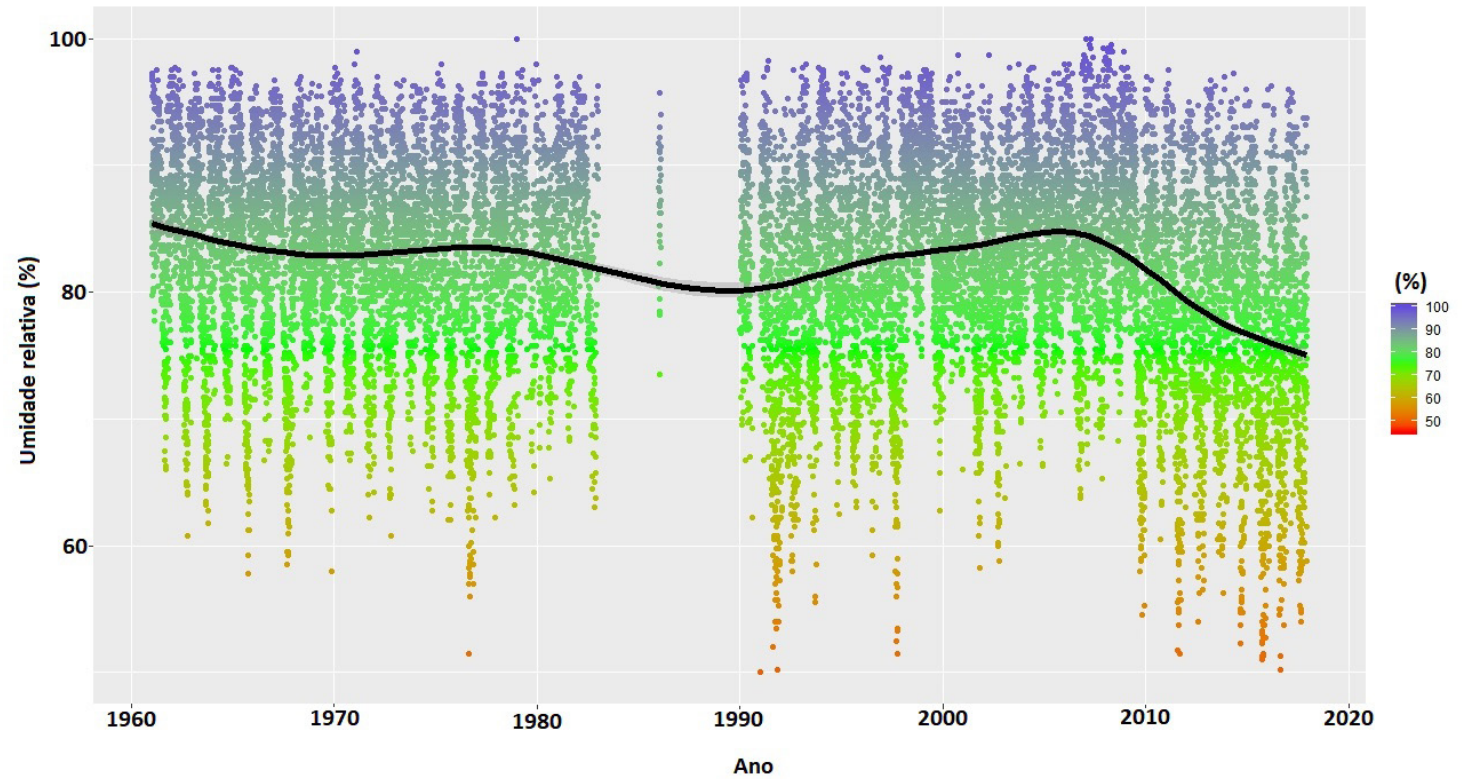

Figura 3 - Médias diárias de umidade relativa do ar da cidade de Manaus/AM para o período de 1961 a 2017. 
Os eventos de temperaturas mais altas estão associados com eventos de $\mathrm{El}$ Niño, como os que ocorreram nos anos de 1982 e 1998, assim como mostram associações com os anos recentes de secas históricas que ocorreram na Amazônia, como no ano de 2010 e 2015. Santos et al. (2012) destacaram os El Niños de 1982-83 e 1997-98 e os La Niñas de 1972-76 e 1983-86, como os eventos de maior influência nas variabilidades das temperaturas do ar em Manaus até aquele ano, assim como os eventos de El Niño contribuíram de forma significativa com o aumento da temperatura média na cidade de Manaus e que os eventos de La Niña contribuíram para anomalias negativas da temperatura média do ar na cidade, o que é corroborado pelos resultados aqui expostos.

A temperatura mais baixa ocorreu em 1991, ocasionado pela entrada de uma frente fria (friagem) na cidade, resultado de entrada de massa de ar polar que ocasionalmente adentram no estado do Amazonas e ocasionam intensas diminuições na temperatura do ar (Ribeiro, 2012). Outras cidades do estado, já demostraram valores médios similares em eventos de incursão de ar frio na região, como em Lábrea $\left(11,8^{\circ} \mathrm{C}\right)$, Benjamin Constant $\left(13^{\circ} \mathrm{C}\right)$ e Eirunepé $\left(13,2^{\circ} \mathrm{C}\right)$ em relação a observações horárias (Ribeiro, 2012). Os anos de El Niño são mais quentes e mais secos, implicando em menores médias de umidade relativa do ar, como o recorde mínimo de $45 \%$ ocorrido em 2015.

Anos de La Niña tendem a ter elevadas umidades relativas, como o máximo de $100 \%$ de 2007, tido como um ano de La Niña moderado (Coutinho et al., 2018). A evaporação medida pelo evaporímetro de piche (Figura 4) associa altas taxas de evaporação a anos mais quentes e secos e baixas taxas de evaporação a anos mais frios e úmidos, onde os maiores valores de evaporação podem atingir até os $18 \mathrm{~mm} \mathrm{dia}^{-1}$. A evaporação total média foi de $817 \mathrm{~mm} /$ ano e a maior evaporação total foi observada no ano de 1997 (1501,06mm/ano), classificado com ano de El Niño forte, sendo a menor no ano de 2009 (560,09mm/ano), que teve influências do evento moderado de La Niña, que iniciou no ano de 2008 (Estivallet et al., 2009).

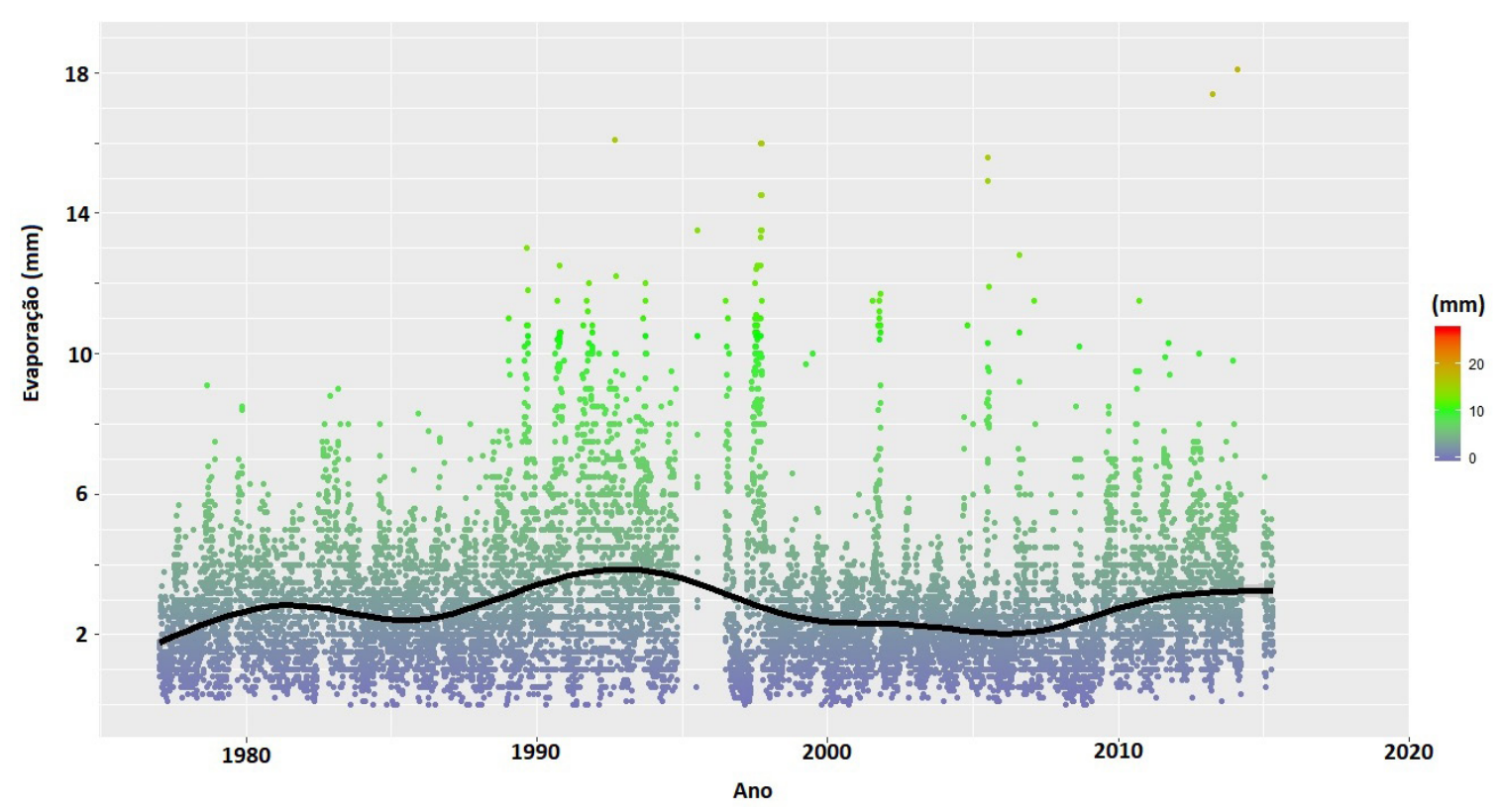

Figura 4 - Médias diárias de evaporação (evaporímetro de piche) da cidade de Manaus/AM para o período de 1961 a 2017.

A relação de aumento de temperatura do ar com o aumento na evaporação em áreas da Amazônia foi apontada por Nobre et al. (2007) $e$ em um contexto de mudanças climáticas $e$ elevação da temperatura do ar, este efeito pode ocasionar uma aceleração do ciclo hidrológico na região. As maiores médias de temperatura do ar (Figura 5) ocorrem nos meses de setembro e outubro, $e$ as menores nos meses de fevereiro $e$ março. A sazonalidade por vezes é afetada 
pelo ENOS, que geram valores de outliers e/ou extremos na série em diferentes épocas do ano, tanto para eventos muito acima quanto muito abaixo da média mensal. Essa grande variabilidade intra-anual é melhor visualizada na densidade de distribuição dos dados de temperatura do ar (Figura 6), onde o mês de outubro tem densidade de dados que podem variar do mínimo da distribuição de dados (em torno de $22,5^{\circ} \mathrm{C}$ ) até a faixa dos $33,5^{\circ} \mathrm{C}$. Principalmente os meses mais quentes apresentam as maiores variabilidades. A maior densidade de ocorrências se dá na faixa em torno de $26,9^{\circ} \mathrm{C}$ e ocorreram no mês de junho (Figura 7).

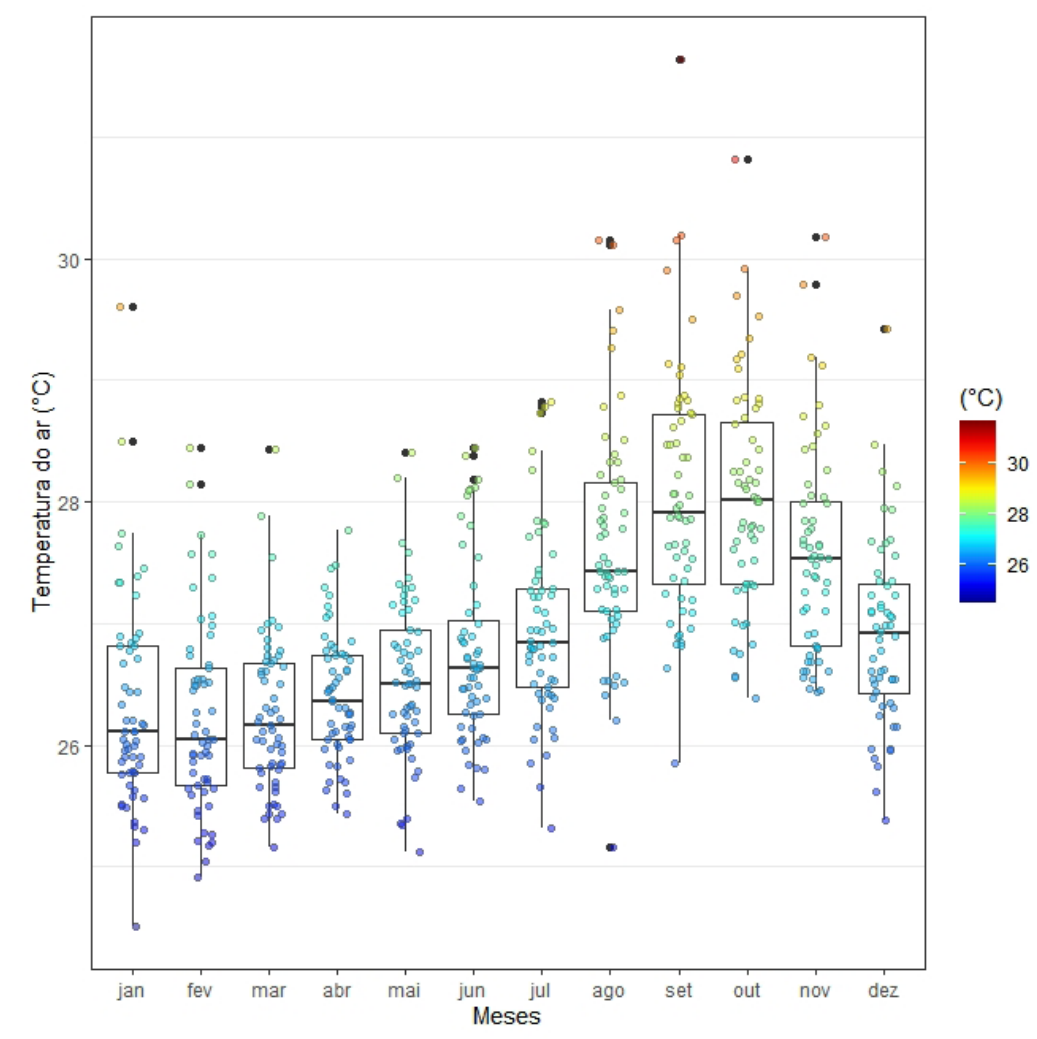

Figura 5 - Boxplot das médias mensais de temperatura do ar $\left({ }^{\circ} \mathrm{C}\right)$ observada na estação meteorológica localizada no município de Manaus para o período de 1961 a 2017.

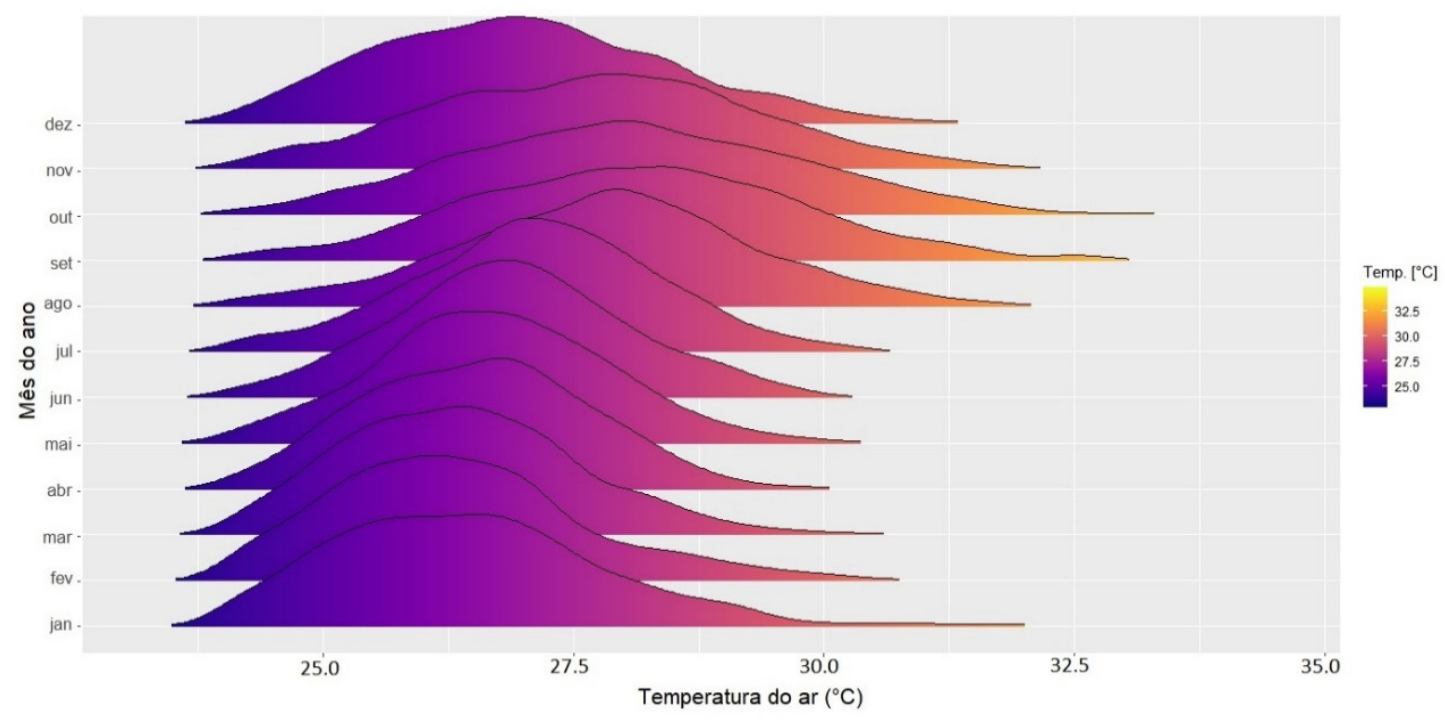

Figura 6 - Densidade de frequência dos dados de temperatura do ar por mês do ano na estação meteorológica localizada no município de Manaus para o período de 1961 a 2017. 


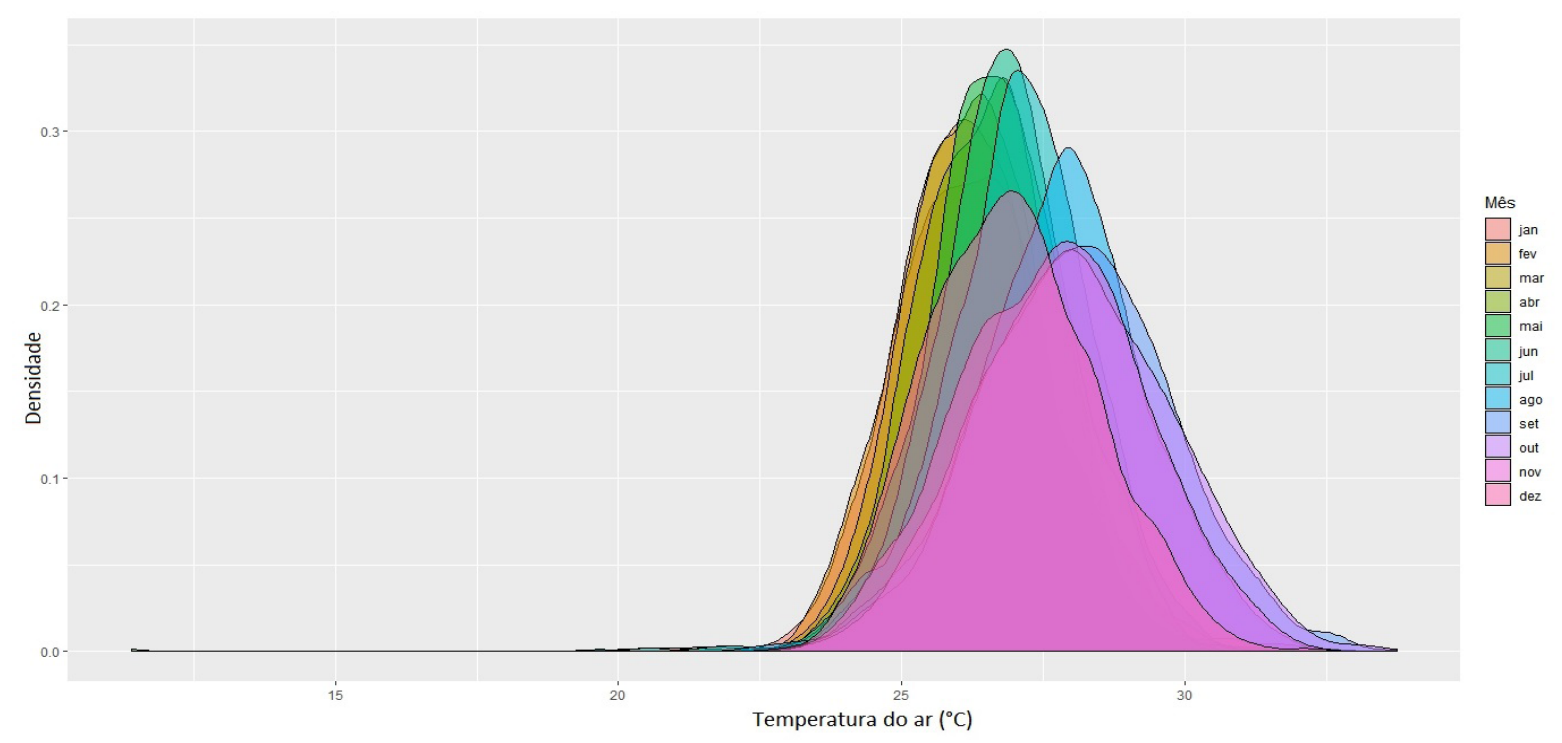

Figura 7 - Valores mensais de densidade dos dados de temperatura do ar da estação meteorológica localizada no município de Manaus para o período de 1961 a 2017.

A média de horas de brilho solar (insolação) é de $5 \mathrm{~h}$, para todo o período avaliado e os máximos de temperatura do ar (setembro) ocorrem aproximadamente 1 mês após o máximo de insolação média mensal (aproximadamente 8h) no mês de julho (Figura 8), o que se explica devido o acúmulo de dias sem chuva aumentar gradativamente a temperatura local. $\mathrm{O}$ mês de transição entre as estações mais e menos chuvosa (maio) tem outliers provavelmente devido à alternância de dias chuvosos e de céu claro. Outliers de menores valores de insolação em meses climatologicamente menos chuvosos estão associados com eventos de La Niña, que aumentam as chuvas na cidade e consequentemente a cobertura por nuvens (Oliveira et al., 2006).

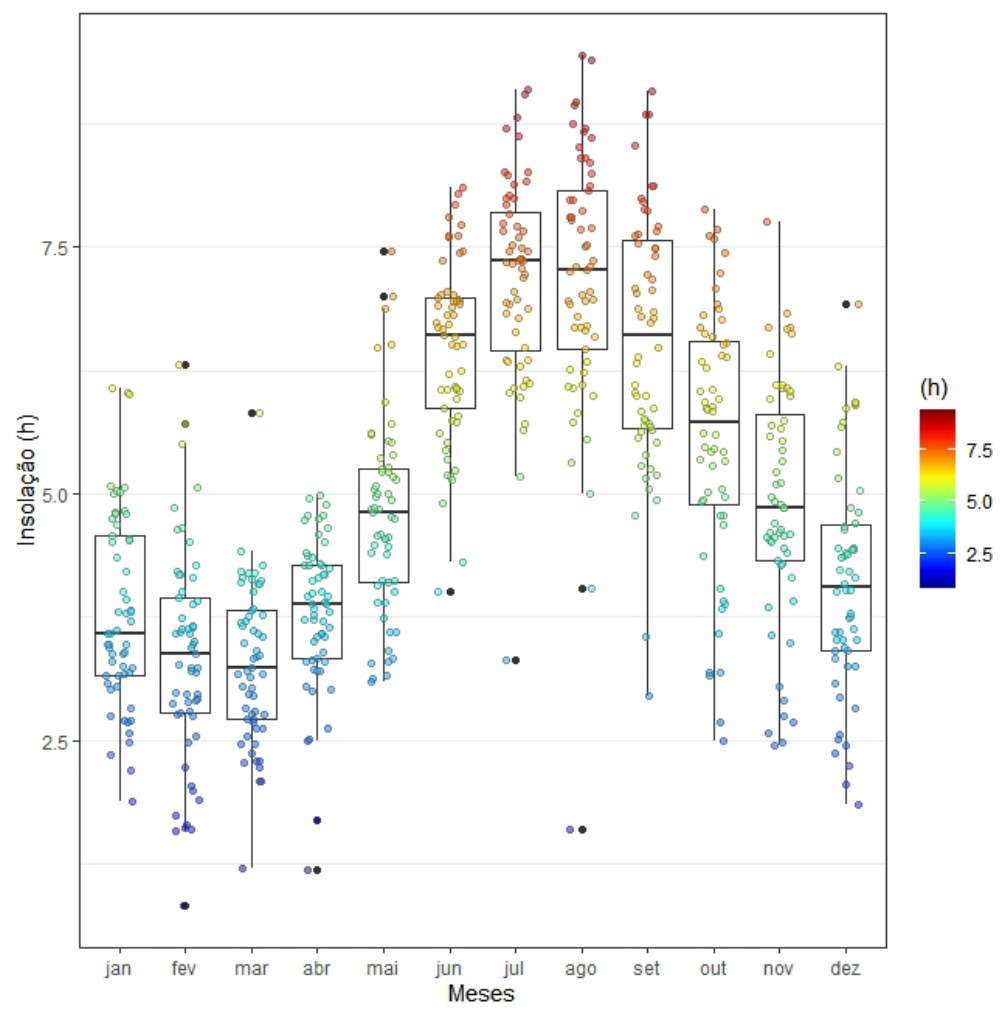

Figura 8 - Boxplot das médias mensais de insolação da cidade de Manaus/AM para o período de 1961 a 2017. 
Os acumulados anuais de precipitação pluviométrica (Figura 9) entre 1961 e 2017 oscilaram entre $1.259 \mathrm{~mm}$ (1982) e $3.157 \mathrm{~mm}$ (2008), classificados como anos de forte El Niño e La Niña moderado respectivamente. Há uma associação positiva em anos de El Niño com ocorrências de totais muito abaixo da média (como os eventos dos anos 1979, 1982, 1987, 1998, 2010 e 2015) $e$ anos de La Niña com totais muito acima da média (como os eventos dos anos 1968, 1989 e 2008), exceto poucos anos de exceções. Sobre a sazonalidade mensal, a Figura 10 mostra os meses de novembro a maio com maior pluviosidade (acumulados mensais acima dos $300 \mathrm{~mm}$ ), e os meses de junho a outubro como os de menor pluviosidade, com médias dos acumulados mensais variando entre 100 a $305 \mathrm{~mm} / \mathrm{mês}$, o que está de acordo com outros estudos (Benedetto, 2014).

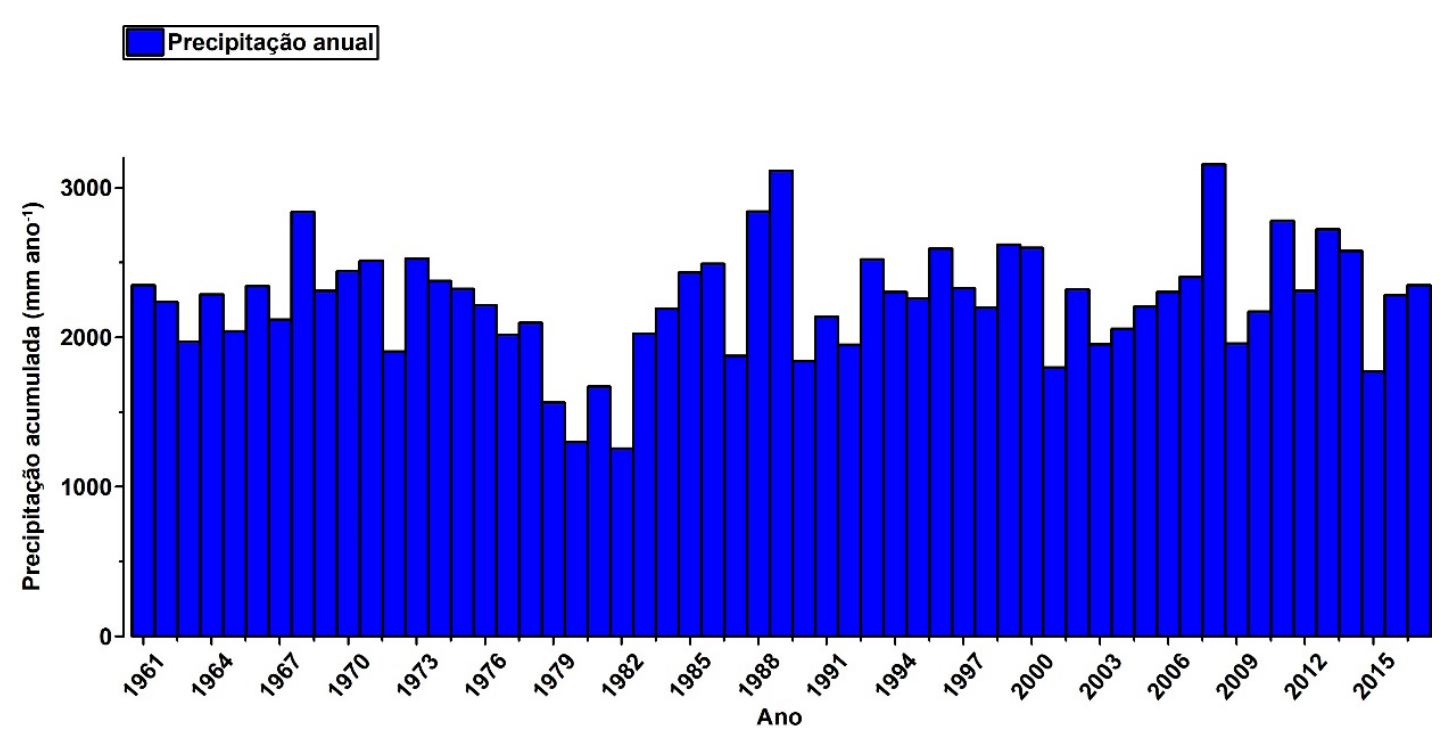

Figura 09 - Totais acumulados anuais de precipitação em Manaus/AM para o período de 1961 a 2017.

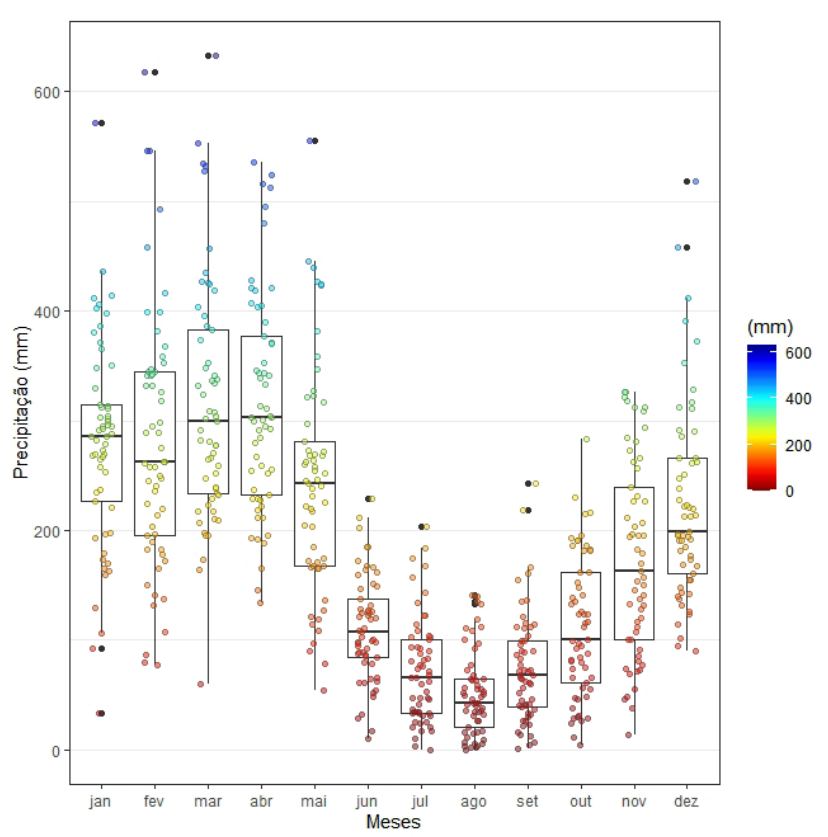

Figura 10 - Boxplot da precipitação da cidade de Manaus/AM para o período de 1961 a 2017. 
Alguns estudos, como Marengo (1992) e Marengo \& Hastenrath (1993), investigaram os mecanismos envolvidos na variabilidade da precipitação na Amazônia em anos de ocorrência de eventos do ENOS. Concluíram que durante eventos de La Niña no final do Verão, uma anomalia no deslocamento da ZCIT seria a responsável por tornar a atmosfera mais úmida na Amazônia, o que se aplica para Manaus ao analisarmos os dados de chuva e umidade da série aqui exposta.

A média de velocidade do vento diária do período é de $1,7 \mathrm{~m} \mathrm{~s}^{-1}$, podendo atingir máximos de velocidade média diária em torno de $11 \mathrm{~m} \mathrm{~s}^{-1}$, sendo o mês de outubro e os demais meses menos chuvosos os que possuem maior intensidade dos ventos (Figura 11). Em Manaus, os ventos mais fortes geralmente ocorrem em conjunto com as chuvas da época mais seca, onde estas são consequências da alta temperatura (Benedetto, 2014). (Corbella \& Yannas, 2009) afirmam que o adensamento das áreas urbanas, como o que aconteceu em Manaus nas últimas décadas, são algumas das mudanças que podem interferir significativamente na velocidade, intensidade $e$ sentido do vento em meio urbano, com alteração do microclima local.

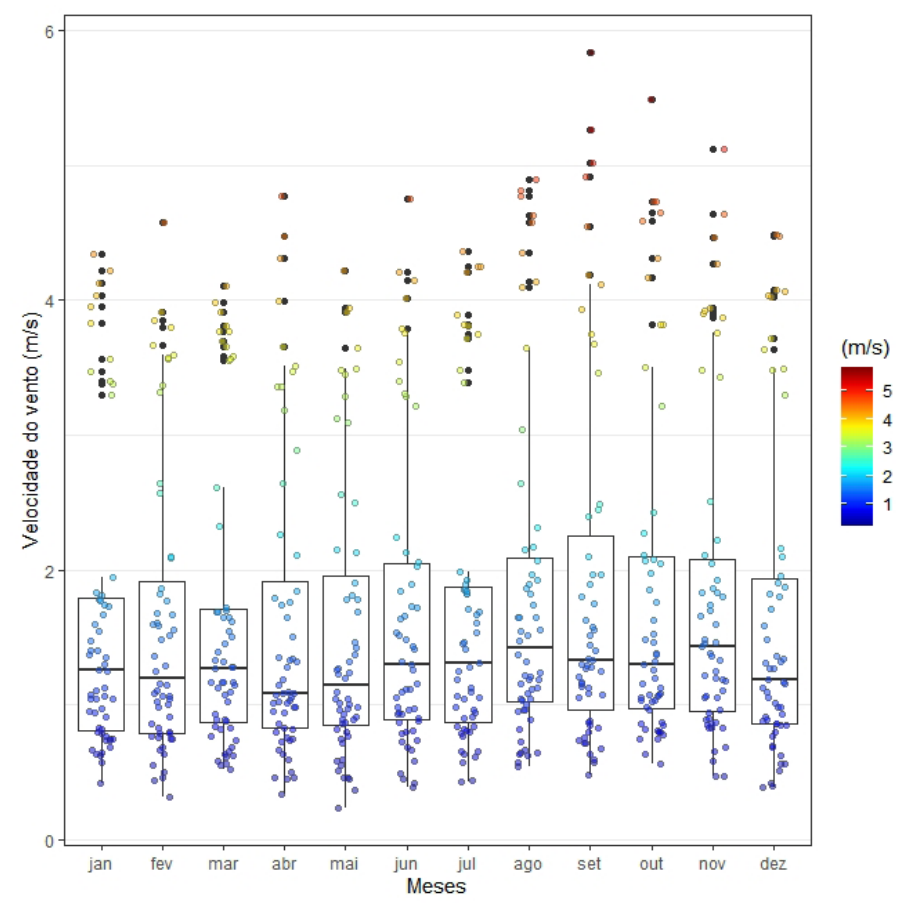

Figura 11 - Boxplot mensal da velocidade média do vento a 10m da cidade de Manaus/AM no período de 1961 a 2017.

Quanto aos padrões de direção de vento (Figura 12), há ocorrência de ventos de todas as direções, com maiores frequências de direção de leste $(\mathrm{E})$, seguidas das de nordeste $(\mathrm{NE})$. A maior frequência dessas direções se dá, principalmente, na transição entre anos DJF, como mostra a (Figura 13), embora nos demais períodos do ano essas frequências também sejam mais frequentes. Tais frequências são decorrentes do sistema de grande escala que ocorre na região (ventos alísios), provenientes das duas altas subtropicais dos oceanos Atlântico Norte e Sul, descritos desde os primeiros trabalhos de Riehl (1965). 


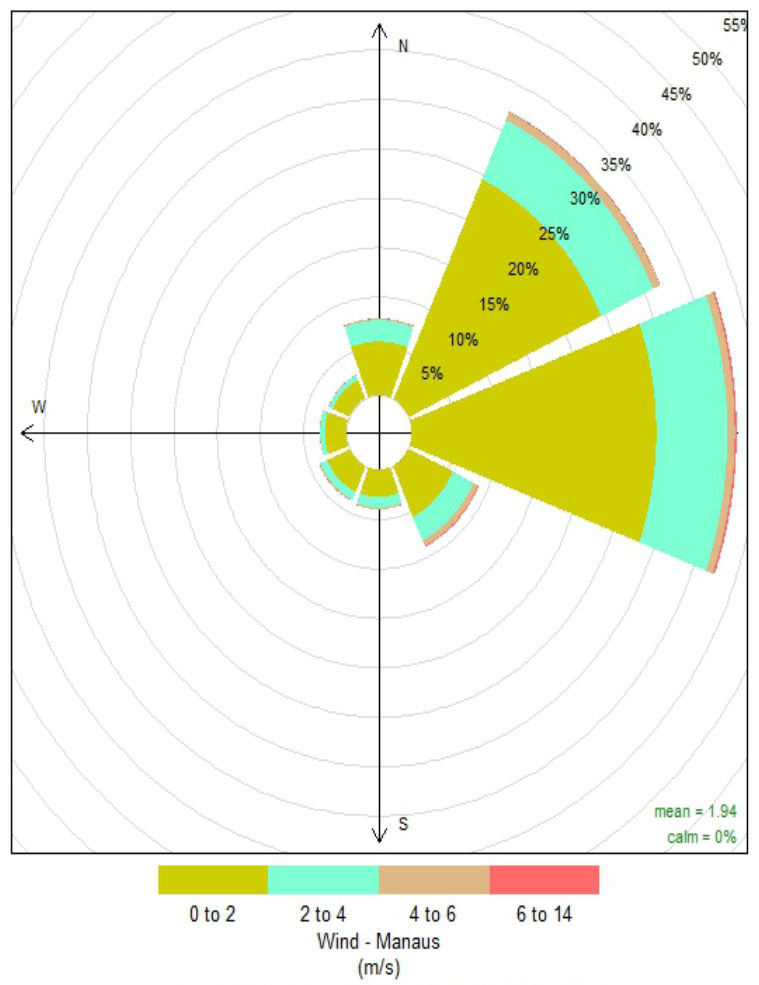

Frequency of counts by wind direction (\%)

Figura 12 - Anemogama (rosa dos ventos) de dados horários observados da direção do vento a 10m da cidade de Manaus/AM para o período de 1961 a 2017.

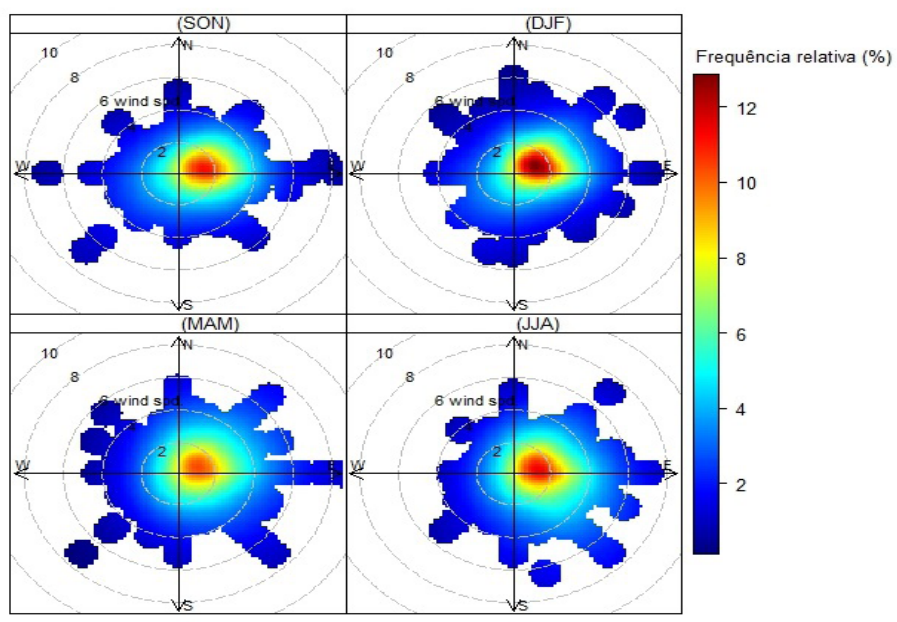

Figura 13 - Frequência relativa sazonal trimestral (em \%) da direção do vento a 10m da cidade de Manaus/AM para o período de 1961 a 2017.

\section{Conclusões}

Os dados sobre máximos, mínimos, médias e associações com fenômenos de grande escala permitiu a caracterização dos aspectos climatológicos sobre a cidade de Manaus, tendo o período de 1961 a 2017, apresentado os valores médios de temperatura, umidade relativa, acumulados médios anuais de precipitação, médias de evaporação, horas de brilho solar e padrões de direção e velocidade do vento condizente com outros artigos da literatura sobre o clima da região 
e proporcionando estatísticas e delineamento de padrões atmosféricos que podem ser consultados para aprimoramento do planejamento urbano da cidade. As ocorrências de El Niño e La Niña se mostraram bem correlacionados com os extremos das variáveis meteorológicas, principalmente quanto aos máximos de temperatura (anos de El Niño), máximos de precipitação (anos de La Niña) e anos com totais pluviométricos abaixo da média (anos de El Niño), sendo as principais informações novas apontadas no trabalho uma tendência de aumento das médias de temperatura com consequente diminuição das médias de umidade relativa do ar como efeito provável do aumento urbanístico da cidade nos últimos anos, associadas com a ocorrência dos recordes máximos de temperatura do ar e mínimo de umidade relativa da série em anos recentes.

\section{Agradecimentos}

A primeira autora agradece ao CNPq pela concessão de bolsa de iniciação científica durante a realização do trabalho. Os autores agradecem aos avaliadores pelas valiosas contribuições na melhoria do artigo.

\section{Referências}

Aguiar DG. Análise da variação sazonal da precipitação e temperatura em Manaus (AM). 2f. Dissertação (Clima e Ambiente (CLIAMB)) - Instituto Nacional de Pesquisas da Amazônia, Manaus, 2017.

Alcoforado MJ. O clima da região de Lisboa: Contrastes e ritmos térmicos. Centro de Estudos de Lisboa/ Universidade de Lisboa. Lisboa. 1993.

Benedetto HMM. Eventos extremos de chuva e vento em Manaus/AM de 2002 a 2012. 20 f. Relatório final (iniciação científica) - Universidade Federal do Amazonas. 2012.

Corbella O \& Yannas S. Em Busca de Uma Arquitetura Sustentável Para os Trópicos: conforto ambiental. 2. ed. rev. e ampl. Rio de Janeiro: Revan, 2009.

Coutinho EC et al. Variabilidade climática da precipitação na bacia amazônica brasileira entre 1982 e 2012. Revista Brasileira de Climatologia, 22: 476-500, 2018.

Estivallet J, Oliveira R, Sheuer P, Silva L \& Espíndola LP. La Niña e El Niño: A Influência nas ocorrências tornádicas em Santa Catarina. Monografia (Curso Técnico de Meteorologia) - Instituto Federal de Santa Catarina, Florianópolis, 2009, p.150.
Ferreira SJ, Luizão FJ \& Dallarosa RLG. Precipitação interna e interceptação da chuva em floresta de terra firme submetida à extração seletiva de madeira na Amazônia Central. Acta Amazônica, 1(35): 55-62. 2005.

Fisch G, Marengo JA \& Nobre AC. Uma revisão geral sobre o clima da Amazônia. Acta Amazônica, 2(28): 101-126. 1998.

Gartland L. Ilhas de Calor: como mitigar zonas de calor em áreas urbanas. Tradução de Sílvia Helena Gonçalves. Oficina de Textos, São Paulo. 248p. 2010.

Golden Gate Weather Services. El Niño and La Niña Years and Intensities Based on Oceanic Niño Index (ONI). 2016. Disponível em: http://ggweather.com/ enso/oni.htm. Acesso em 20 set 2018.

Lemos GBde. Precificação de derivativos climáticos no Brasil: uma abordagem estatística alternativa $e$ construção de um algoritmo em R. Tese de Doutorado. Universidade de São Paulo. 161p. 2014.

Marengo, J. Interannual variability of surface climate in the Amazon basin. Int $\mathrm{J}$ Climatol 12: 853-863. MARENGO, J., HASTENRATH, S. 1993: Case studies of extreme climatic events in the Amazon basin. Journal of Climate, 6: 617-617. 1992.

Marengo J \& Hastenrath S. Case studies of extreme climatic events in the Amazon basin. Journal of Climate, 6: 617-617. 1993.

Molion LCB. Amazonia rainfall and its variability. In: Hydrology and water manegement in the humid tropics. Bonell M, Hufschmidt MM \& Gladwell JS (eds.). International Hydrology Series, Cambrigde University Press, p. 99-111. Cambridge. 1993.

Nobre CA, Sampaio G \& Salazar L. Mudanças climáticas e Amazônia. Cienc. Cult., São Paulo, 59(3): 22-27. 2007.

Oliveira FNMD, Araújo RLCD, Carvalho JDS \& Silva CLD. Inferência de Mudanças Climáticas na Região de Manaus (AM) Usando Dados Geotermais e Meteorológicos. Revista Brasileira de Geofísica, 24(2): 169-187. 2006.

Ribeiro IL. As incursões de ar frio no Estado do Amazonas. 2012. 88 f. Dissertação (Mestrado em Geografia) - Universidade Federal do Amazonas, Manaus. 2012.

Riehl H. Meteorologia tropical, Centro de Publicações Técnicas da Aliança. Tradução de Aurélio Augusto Rocha, Rio de Janeiro. 1965.

Salati E. O clima atual depende da floresta. In: Salati E, Junk WJ, Schubart HOR \& Oliveira A. (Eds), Amazônia, desenvolvimento, integração e ecologia. São Paulo, Brasiliense, p. 15-44. 1983. 
Santos CAC, Satyamurty P \& Santos EM. Tendências de índices de extremos climáticos para a região de Manaus/AM. Acta Amazonica. 42: 329-336. 2012.

Silva DADa \& Aguiar FEO. Ilha de Calor Urbana na Cidade de Manaus: Especulação ou realidade? Revista Geonorte, 6(1): 49-65. 2012.

Souza EB \& Ambrizzi T. ENSO Impacts on The South American Rainfall during 1980s: Hadley and Walker Circulations. Atmósfera. 15: 105-120. 2002.
Souza EB, Kayano MT \& Ambrizzi T. Intraseazonal and Submonthly Variability over the Eastern Amazon and Northeast Brazil during the Autumn Rainy Season. Theoretical and Applied Climatology. 81: 177-191. 2005.

WMO (World Meteorological Organization) n 1186. Guidelines on Climate Metadata and Homogenization. Secretariat of the World Meteorological Organization, Geneva, 2003.

Biodiversidade Brasileira - BioBrasil.

Edição Temática: Análise de Componentes do Sistema Climático e a Biodiversidade no Brasil

$$
\text { n. 4, } 2021
$$

http://www.icmbio.gov.br/revistaeletronica/index.php/BioBR

Biodiversidade Brasileira é uma publicação eletrônica científica do Instituto Chico Mendes de

Conservação da Biodiversidade (ICMBio) que tem como objetivo fomentar a discussão e a disseminação de experiências em conservação e manejo, com foco em unidades de conservação e espécies ameaçadas.

ISSN: 2236-2886 